\title{
LIGHT STIMULATED $\triangle$-AMINOLEVULINATE ACCUMULATION IN LEVULINATE TREATED BARLEY SEEDLINGS
}

\author{
by \\ SIMON P. GOUGH* \\ Department of Physiology, Carlsberg Laboratory, \\ Gamle Carlsberg Vej 10, DK-2500 Copenhagen Valby \\ * The experimental part of this work was carried out at the laboratory \\ of Dr. Sam Granick, Rockefeller University, New York, USA, and this paper \\ is dedicated to his memory.
}

Keywords: Feedback, inhibition, enzyme turnover, cytoplasmic protein synthesis, photosynthesis

In dark-grown barley shoots treated with levulinate and briefly illuminated the protochlorophyllide which fails to reform is replaced by an excessive amount of $\delta$-aminolevulinate (ALA). This accumulation of ALA is strongly inhibited by $100 \mu \mathrm{g} \cdot \mathrm{ml}^{-1}$ cycloheximide but not chloramphenicol or actinomycin $\mathrm{D}$. In darkness levulinate treated shoots form only little ALA; in light ALA forms at an increasing rate reaching a maximum after 2 to 3 hours. When returned to the dark the rate of ALA formation decays to a low level. Cycloheximide does not prevent this decay. Subsequent illumination results in a rise in the rate of ALA accumulation slightly inhibited by cycloheximide pretreatment. The rate of ALA formation during greening is not initially sensitive to DCMU $\left(10^{-4}-\mathrm{M}\right)$ but is progressively inhibited up to $45 \%$ by 18 hours. It is concluded that light causes the synthesis of ALA by enzymes already present in dark-grown barley as well as the synthesis of the ALA forming enzymes on cytoplasmic ribosomes. In a dark period after formation of the enzymes during greening feedback inhibition is exerted by anabolic products of ALA although regulation of the enzymes through turnover also occurs. In later stages of greening light stimulates ALA formation through photosynthesis.

\section{INTRODUCTION}

Chlorophyll synthesis is known to be regulated at the level of its precursor $\delta$-aminolevulinate. Levulinate, the competitive inhibitor of $\delta$-aminolevulinate dehydratase proved a useful tool to analyse the formation of $\delta$-aminolevuli- nate (ALA) in Chlorella (1) and Zea mays (6). As a preliminary for the analysis of mutants in barley which are defective in the regulation of chlorophyll synthesis, levulinate has been used to follow the light induced formation of ALA in wild type barley seedlings. 
Table I

Mineral salt solution. The nutrients were added to distilled water in the order given.

\begin{tabular}{|c|c|c|}
\hline Stock solution & $\begin{array}{l}\mathrm{ml} \text { stock solution } \\
\text { per litre nutrient } \\
\text { solution }\end{array}$ & $\begin{array}{l}\text { Concentration } \\
\text { nutrient solution } \\
\text { (mM) }\end{array}$ \\
\hline \multicolumn{3}{|l|}{ Macronutrients } \\
\hline 1. $1 \mathrm{M} \cdot \mathrm{Ca}\left(\mathrm{NO}_{3}\right)_{2} \cdot 4 \mathrm{H}_{2} \mathrm{O}$ & 5 & 5 \\
\hline 2. $0.5 \mathrm{M}-\mathrm{K}_{2} \mathrm{SO}_{4}$ & 4 & 2 \\
\hline 3. $1 \mathrm{M}-\mathrm{MgSO}_{4}$ & 4 & 4 \\
\hline 4. $1 \mathrm{M}-\mathrm{NH}_{4} \mathrm{H}_{2} \mathrm{PO}_{4}$ & 1 & 1 \\
\hline \multicolumn{3}{|l|}{ Micronutrients } \\
\hline 5. $90 \mathrm{mM}-\mathrm{KFelII}$ Ethylenediaminetetraacetate & 1 & 0.090 \\
\hline 6. $0.1 \mathrm{mM}-\mathrm{MoO}_{3}$ & 0.1 & 0.0001 \\
\hline 7. $9.2 \mathrm{mM}-\mathrm{H}_{3} \mathrm{BO}_{3}$ & 0.1 & 0.0092 \\
\hline 8. $1 \mathrm{mM}-\mathrm{CuSO}_{4} \cdot 5 \mathrm{H}_{2} \mathrm{O}$ & 0.1 & 0.001 \\
\hline 9. $1 \mathrm{mM}-\mathrm{MnSO}_{4} \cdot 4 \mathrm{H}_{2} \mathrm{O}$ & 0.1 & 0.018 \\
\hline 10. $3.8 \mathrm{mM}-\mathrm{ZnSO}_{4} .7 \mathrm{H}_{2} \mathrm{O}$ & 0.1 & 0.0038 \\
\hline
\end{tabular}

The $\mathrm{pH}$ of the nutrient solution after additions was 5.0.

\section{MATERIALS AND METHODS}

\subsection{Plant material}

Seeds of barley (Hordeum vulgare L.cv. Svalöfs Bonus) were germinated and grown in the dark at $25 \pm 2{ }^{\circ} \mathrm{C}$ in closed cabinets on vermiculite watered with a mineral salt solution. Seedlings were manipulated under a green safelight.

It was found that plants grown in the dark on mineral salt solution modified from (7), developed faster, with unrolled leaves compared to those grown on tap water. These shoots imbibed experimental solutions more readily than did shoots from seedlings grown on tap water. Therefore, unless otherwise indicated the seedlings were watered throughout the growth period with the nutrient solution given in Table I.

\subsection{Levulinate treatment and infiltration of shoots}

Seedlings were cut with a sharp razor blade and the cut end of the shoot immersed in a
$20 \mathrm{~mm}-\mathrm{Na}$-levulinate solution $\mathrm{pH} 6.5$ for 2 hours in the dark. During further experimentation the shoots were kept in the levulinate solution.

For infiltration shoots were totally immersed with their bases upwards in the appropriate solutions and a vacuum of $76200 \mathrm{~Pa}$ applied for half a minute, released, re-applied and released.

\subsection{Light sources and intensities}

The electronic flash used was a Zeiss Whatron microflash unit. Light intensities were measured in $\mathrm{mWatt} \cdot \mathrm{cm}^{-2}$ by a thermistor (YSIKettering Model 05 Radiometer) and in $\mathrm{ft}$ candles by a General Electric exposure meter. The designation "high light intensity“ is used for 1.2 to $1.4 \mathrm{mWatt} \cdot \mathrm{cm}^{-2}$ from Gro-Lux, F40-GRO fluorescent light also measured as $500 \mathrm{ft}$ candles by the exposure meter. "Low intensity light" is fluorescent room lighting and was measured as $25 \mathrm{ft}$ candles by the exposure meter.

Abbreviations: ALA = $\delta$-aminolevulinic acid; DCMU =3-(3,4-dichlorophenyl) -1,1-dimethylurea. 


\subsection{Determination of accumulated ALA and of green pigments}

After an experiment shoots were stored in liquid nitrogen until the time of analysis. Shoots were kept in the deep-frozen state by temporary storage in $\mathrm{CO}_{2}$ snow until immediately before homogenisation.

\subsubsection{Homogenisation of leaves}

1 to 2 grams of frozen leaves were homogenised in $0.6 \% \mathrm{NaHCO}_{3}$ with 1 drop of an antifoaming agent (antifoam A, Sigma) using a Vertis homogeniser run at top speed for 1.5 minutes. Portions of the resulting suspension were adjusted to $7.55 \%$ trichloracetic acid and to $80 \%$ acetone respectively, for the determination of ALA and green pigments in the same sample. These mixtures were then centrifuged at $6500 \times \mathrm{g}$ to clarify them.

\subsubsection{Determination of $A L A$}

$0.6 \mathrm{ml}$ portions of the trichloracetic acidsupernatant were adjusted to $\mathrm{pH}$ 4.5-5.0 with $0.3 \mathrm{ml}$ of a mixture of $\mathrm{Na}$-acetate solution and acetyl acetone at $85^{\circ} \mathrm{C}(4 \mathrm{ml}$ saturated $\mathrm{Na}$ acetate, $1.2 \mathrm{ml}$ acetyl acetone adjusted to $12 \mathrm{ml}$ with destilled water at $85^{\circ} \mathrm{C}$ ). The solution at $\mathrm{pH} 4.5$ to 5.0 was then heated at $85^{\circ} \mathrm{C}$ for 10 minutes, cooled to room temperature and 0.9 $\mathrm{ml}$ of modified Ehrlich reagent added. Colour development was measured after 15 minutes (5).

\subsubsection{Determination of green pigments}

The spectra of the $80 \%$ acetone solutions were taken using a Cary-14 spectrophotometer and a cuvette having a light path of $10 \mathrm{~cm}$. The concentration of chlorophyll $a$, chlorophyll $b$ and protochlorophyllide was determined by multilinear regression analysis of the spectra (4).

To allow comparison with ALA concentrations, amounts of green pigments are given as ALA equivalents, i.e., multiplied by 8 , as each molecule of porphyrin is built from 8 molecules of ALA. The extinction coefficients given in Table II were used $(4,15)$. A 4 th series of coefficients is used to take care of possible sloping baselines due to low scatter.

\subsubsection{Multilinear regression analyses}

The absorbance values from the spectra at the 7 or 8 wavelengths, depending on whether the values at $536 \mathrm{~nm}$ were included or not, were transferred to punched cards and regression analyses carried out using a PDP-15 computer and the program MLTRG from STATPAC (statistical package of the machine).

\subsubsection{Determination of photoconvertible protochlorophyllide}

Shoots were cooled in an ice bath and illuminated with the electronic flash. The time between each flash was 3 seconds. After 2 flashes (Figure 1) photoconversion was essentially

\section{Tabel II}

Extinction coefficients used in multiple regression analysis of pigment mixtures.

\begin{tabular}{lcccr}
\hline$\lambda$ & protochlorophyllide $\varepsilon_{\mathrm{mM}}$ & chlorophyll $a \varepsilon_{\mathrm{mM}}$ & chlorophyll $b \varepsilon_{\mathrm{mM}}$ & $700-\lambda$ \\
\hline 700 & 0 & 0 & 0 & 0 \\
665 & 0 & 81.1 & 9.8 & 35 \\
649 & 1.7 & 20.9 & 47.6 & 51 \\
628 & 34.5 & 14.7 & 14.2 & 72 \\
610 & 12.5 & 10.4 & 9.9 & 90 \\
575 & 12.1 & 8.5 & 7.4 & 125 \\
558 & 8.3 & 4.3 & 5.2 & 142 \\
536 & 6.9 & & 5.8 & 164 \\
\hline
\end{tabular}




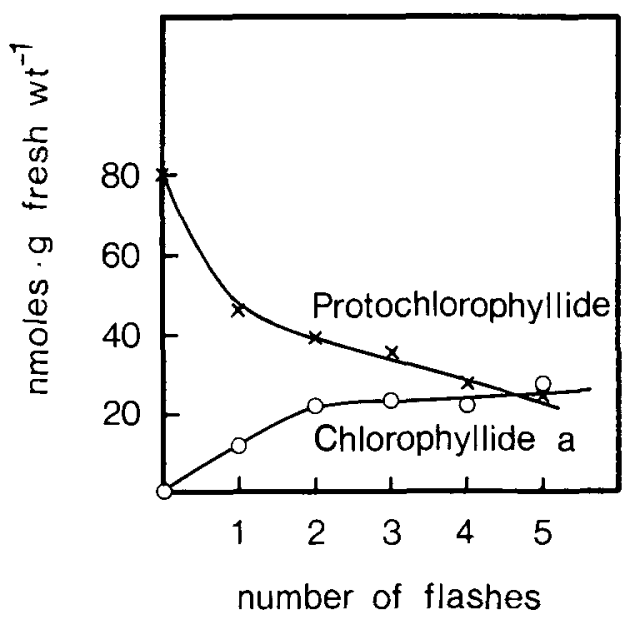

Figure 1. Photoconversion of protochlorophyllide into chlorophyllide by successive flashes (2.4.) in 7-day old dark-grown barley shoots. The amount of pigment is expressed as ALA equivalents (cf. 2.5.3.).

complete and not much more chlorophyll $a$ could be extracted from the shoots after additional flashes. The amount of chlorophyll $a$ measured after two flashes was therefore taken as a measure of the amount of photoactive protochlorophyllide holochrome present.

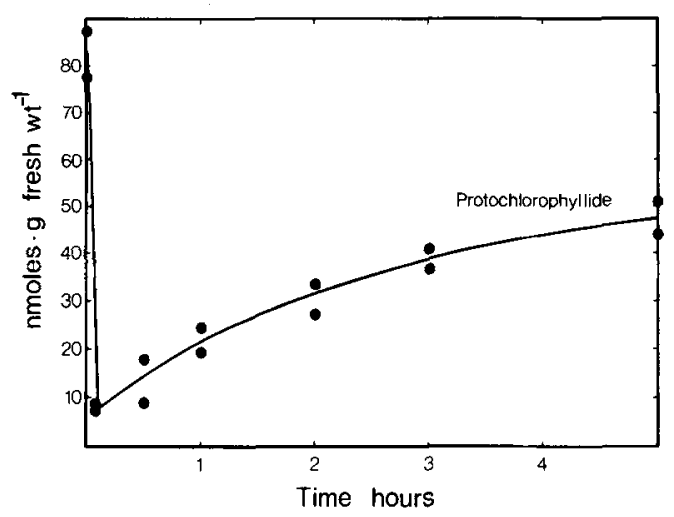

Figure 2. Time course of protochlorophyllide regeneration after a 5 minute period of light. 7-day old dark-grown shoots were incubated for 2 hours on $20 \mathrm{mM}-\mathrm{NaCl}$ and then illuminated for 5 minutes with high light intensity and returned to the dark. Amount of pigment is expressed as ALA equivalents (cf. 2.5.3.).

\section{RESULTS}

In the presence of levulinate, a competitive inhibitor of ALA-dehydratase conversion of ALA to chlorophyll is inhibited and ALA accumulates. ALA formation in barley shoots can therefore be studied by allowing the shoots to imbibe levulinate in a dark period preceding a light treatment. Alternatively, shoots can be vacuum infiltrated (2.2) with levulinate and ALA accumulated over shorter time periods followed.

\subsection{ALA accumulation in dark-grown shoots after 5 minutes of light \\ 3.1.1. The effect of different levulinate concentrations}

In 7-day old barley shoots which have been grown in the dark and subjected to 5 minutes of light a few percent remain of the initially present protochlorophyllide (Figure 2). When returned to the dark the shoots regenerated $60 \%$ of the initial (dark) content of protochlorophyllide in 5 hours. Concentrations of levulinate greater than $10 \mathrm{~mm}$ (Figure 3) inhibit the reaccumulation of protochlorophyllide to a progressively greater extent. At the same time an interesting and excessive accumulation of ALA occurs. It is considered excessive because the amount of ALA which accumulates at $20 \mathrm{~mm}$-levulinate is $30-60$ fold greater than the protochlorophyllide which fails to form. At 35 to $50 \mathrm{~mm}$-levulinate excessive ALA accumulation occurs but protochlorophyllide reformation is more strongly inhibited. At $100 \mathrm{~mm}$ levulinate excess ALA is still formed whereas protochlorophyllide regeneration is very low. Levulinate may cause excess ALA to accumulate by lowering the concentration of an anabolic product of ALA such as protochlorophyllide, protoporphyrin or heme, which regulates ALA formation.

\subsubsection{The accumulation of $A L A$ and regeneration of total photoconvertible protochlorophyllide}

In the presence of $20 \mathrm{~mm}$-levulinate the amount of ALA generated was much greater than the amount of protochlorophyllide which failed to be reformed. In order to see if the overproduction of ALA was related to an 


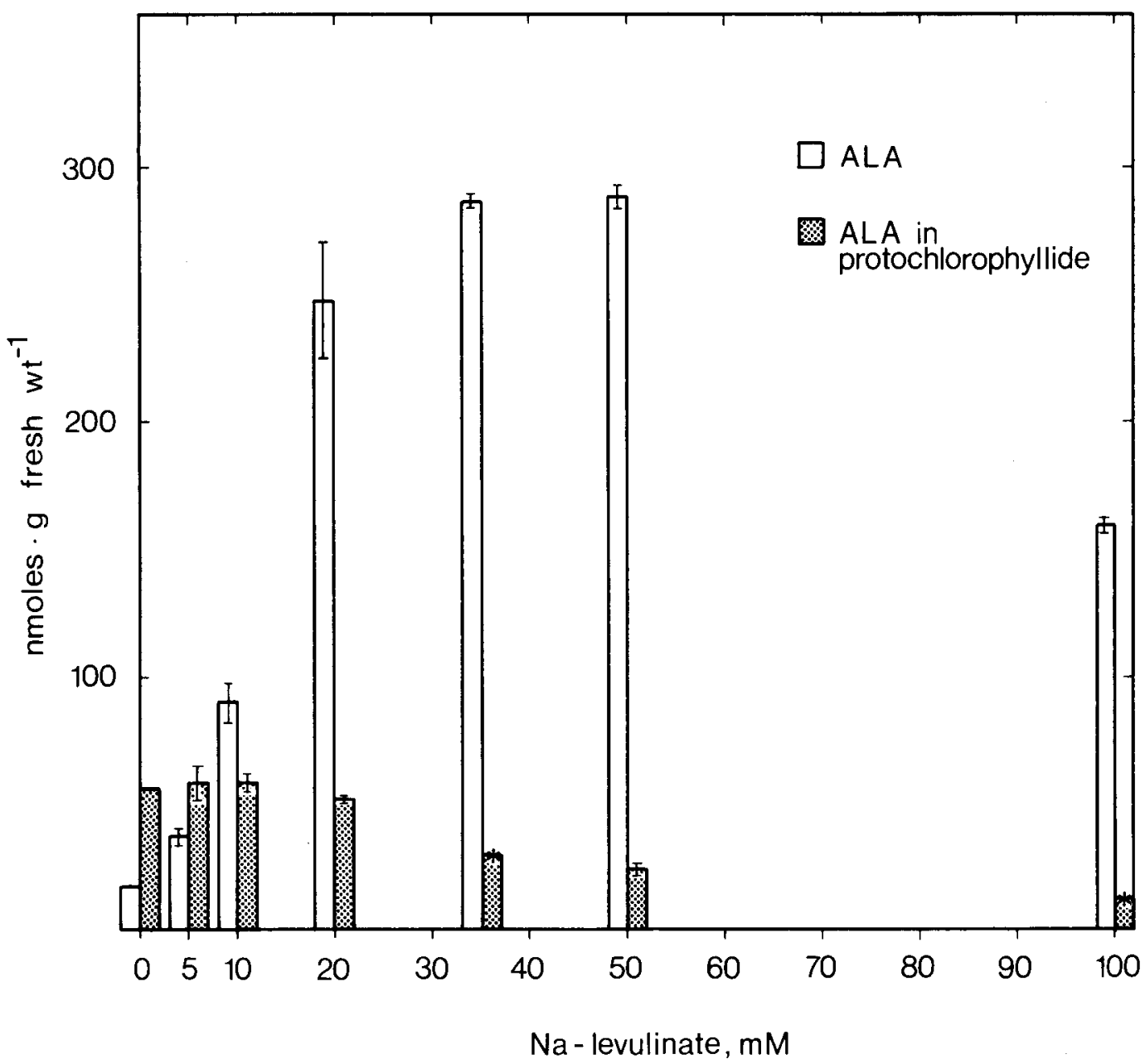

Figure 3. The effect of continuous feeding of various levulinat concentrations on the amount of ALA formed in shoots after a short light period. Dark-grown shoots were incubated in the dark on levulinate then given 5 minutes high intensity light and finally returned to the dark for 5 hours. Bars indicate the spread and $x$ identical values of duplicate determinations.

inhibition of the regeneration of photoconvertible protochlorophyllide or total protochlorophyllide these two parameters were followed as a function of time in the dark, after a light period (Figure 4). The rate of accumulation of ALA is at the start of the dark period similar to that of protochlorophyllide regeneration. After about half an hour the amount of ALA increases exponentially whereas protochlorophyllide continues to form at a linear rate. Photoconvertible protochlorophyllide reforms significantly first after about 1 hour, and remains low throughout the 5 hour period.

As the formation of total and photoconvertible protochlorophyllide levels off between hours 2 and 3, ALA accumulation also reaches saturation. By the third hour the pool of ALA increases at a rate less than that of total protochlorophyllide. In 5 hours protochlorophyllide regenerates to a level similar to that of the chlorophyll initially formed.

In the absence of levulinate total proto- 


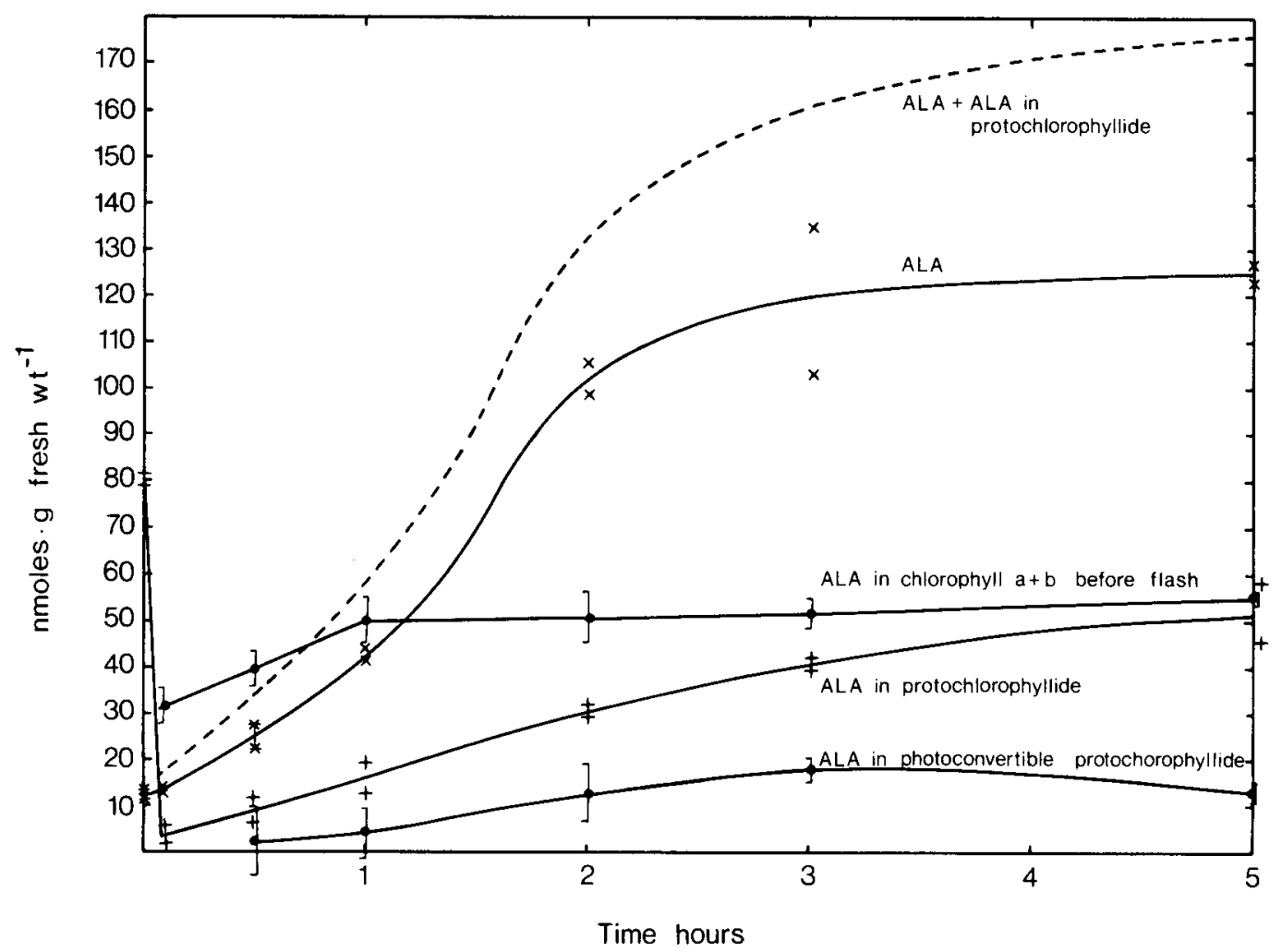

Figure 4. The accumulation of ALA in the presence of levulinate and regeneration of total and photoconvertible protochlorophyllide after a short light period. Dark-grown shoots were incubated in the dark on levulinate, then given 5 minutes of high intensity light and returned to the dark. The spread of duplicate determinations is indicated. The amount of photoconvertible protochlorophyllide present was determined as the difference between the average amount of chlorophyll before and the values after a flash. These values were corrected by dividing them with a factor of 0.55 , since only $45 \%$ of the chlorophyll formed during photoconversion is immediately extractable by the techniques used as seen from the increase of the amount of chlorophyll $a+b$ during the first hour in dark.

chlorophyllide regenerates at an initially linear rate of 17 nmoles ALA per gram fresh weight per hour (Figure 2) apparently mediated by enzymes present in the dark grown seedlings. In the presence of levulinate an initial accumulation of ALA with a comparable rate is actually observed (14 nmoles ALA per gram fresh weight per hour as determined from Figure 4). The light induced increase in the activity of the ALA forming enzymes to 100 nmoles ALA per gram fresh weight per hour becomes apparent in the presence of the ALA-dehydratase inhibi- tor. It is normally not seen because of the feedback inhibition of the ALA forming enzymes which is operative in leaves in the dark after a brief illumination. ALA formation ceases after 3 hours also in the presence of levulinate, probably because the feedback inhibitor by then has reached a sufficient concentration to exert its effect. From the present data it cannot be decided if the accumulation of total protochlorophyllide or the regeneration of active protochlorophyllide holochrome results in the inhibition of ALA production. 


\subsubsection{The effect of cycloheximide, chloramphenicol and actinomycin-D}

The stimulation of ALA formation in the presence of levulinate is strongly inhibited by cycloheximide but not by chloramphenicol or actinomycin-D (Figure 5). In the presence of cycloheximide the total amount of ALA formed (i.e., ALA plus protochlorophyllide) corresponds closely to the amount of protochlorophyllide regenerated in the control. The increase in the activity of the ALA-forming system revealed in the presence of levulinate is therefore completely inhibited by cycloheximide. As cycloheximide is known to be an inhibitor of protein synthesis on cytoplasmic ribosomes it is concluded that the light-stimulated increase in the activity of the ALA-forming system requires active protein synthesis by cytoplasmic ribosomes. Actinomycin-D an inhibitor of transcription and chloramphenicol a specific inhibitor of protein synthesis on chloroplast ribosomes were without effect.

\subsection{ALA formation in continuous light and after return to the dark upon attainment of max- imal ALA forming activity}

Seven-day dark-grown levulinate treated shoots shown continuous light attain a maximal rate of about 100 nmoles ALA accumulated per gram fresh weight per hour at 2.5 hours after the onset of illumination (Figure 6) ALA accu-

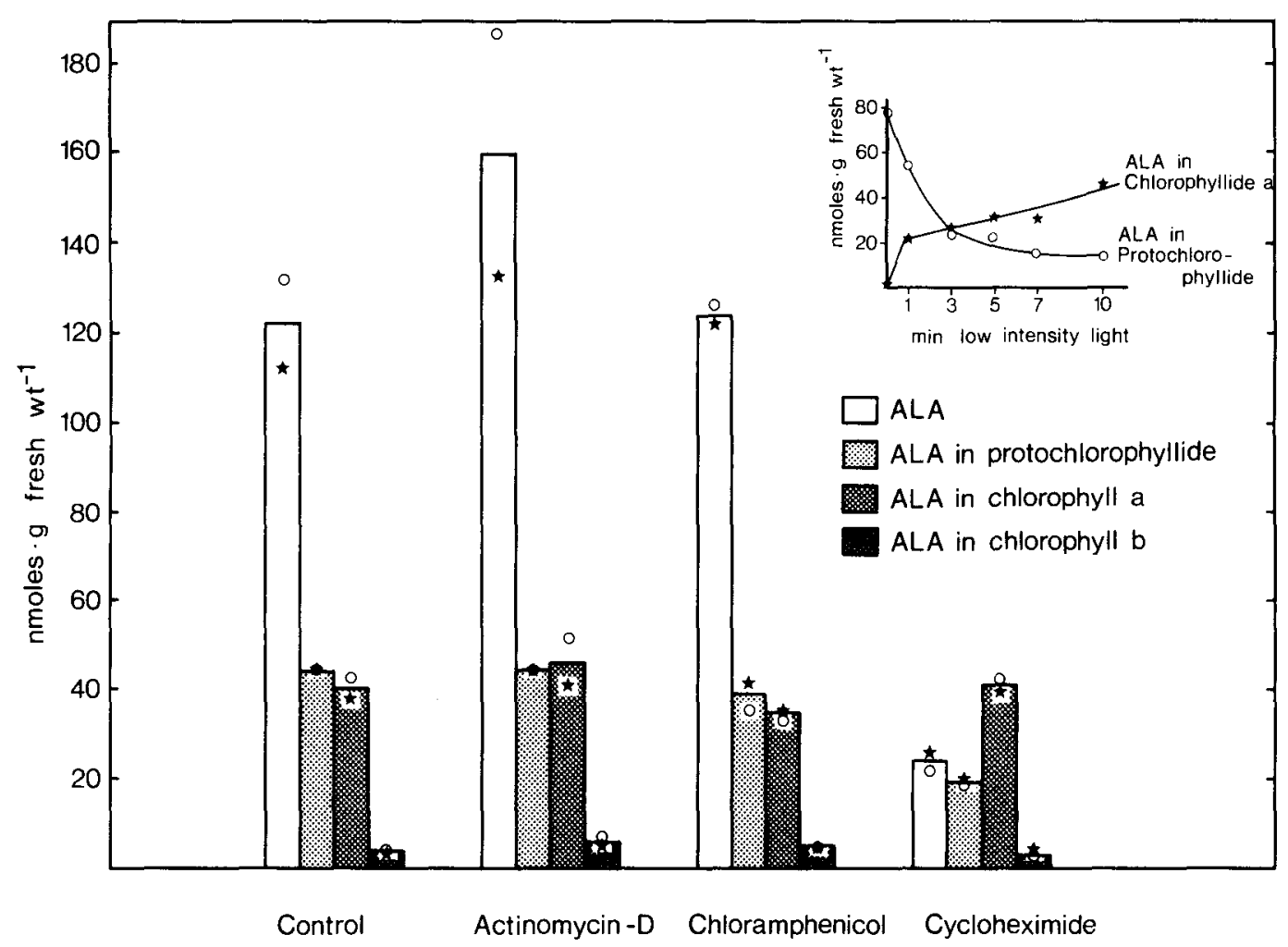

Figure 5. The effect of antibiotics on ALA accumulation and protochlorophyllide regeneration. Dark-grown barley shoots were incubated in the dark on actinomycin-D $\left(100 \mu \mathrm{g} \cdot \mathrm{ml}^{-1}\right)$ chloramphenicol (100 $\left.\mu \mathrm{g} \cdot \mathrm{ml}^{-1}\right)$ cycloheximide $\left(100 \mu \mathrm{g} \cdot \mathrm{ml}^{-1}\right)$ solutions which were $20 \mathrm{mM}$ in $\mathrm{Na}$ levulinate $\mathrm{pH} 6.5$ or on levulinate alone and then illuminated for 6 minutes with low intensity light in order to minimise photodynamic damage due to absorption of light by actinomycin-D. The dissappearance of protochlorophyllide and formation of chlorophyllide in this light is shown in the inset. After the light period the shoots were returned to the dark for $\mathbf{4}$ hours. 


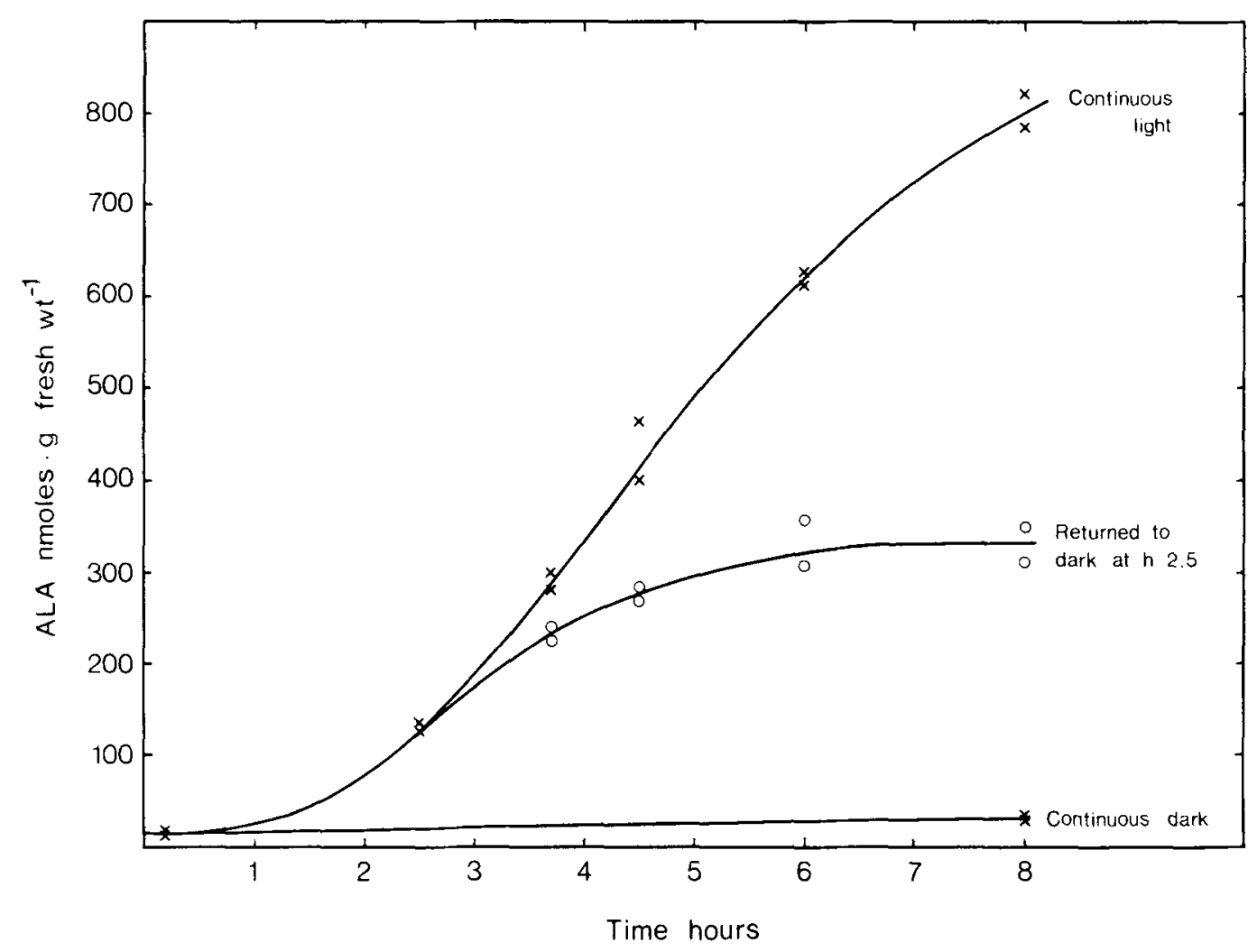

Figure 6. ALA formation in continuous light and dark and the effect of return to the dark at the time when maximal activity of ALA formation in the light is reached.

Dark-grown shoots were treated with levulinate as usual and then kept in the dark or exposed to high light intensity. 2.5 hours after the initial exposure to light some samples were returned to the dark while some remained in the light.

mulation continues over the 8 hour period investigated. Without light induction a very slow accumulation of ALA occurs. Shoots returned to the dark after having attained a maximal rate of ALA accumulation at 2.5 hours after the onset of illumination (Figure 6) gradually cease to accumulate ALA. ALA accumulation decays in the dark with a half-life of 0.86 hours.

The decay in the rate of ALA formation in the dark is not prevented if the shoots are infiltrated with cycloheximide at the time of transfer from the light to the dark at 2.5 hours (Figure 7). The decay thus is not dependent on the synthesis of a protein on cytoplasmic ribosomes.
If at hour 7, i.e., upon completion of the dark decay in the rate of ALA formation shoots are illuminated anew the rate of ALA formation increases more rapidly than at the first illumination (Figure 7). The maximal rate attained is however lower than that reached after the first illumination. Cycloheximide infiltration 1 hour before the second illumination did not prevent a rapid initial rise in the rate of ALA formation but the maximal rate achieved is only $65 \%$ of that of the water control. In contrast to the increase in ALA forming activity after a first illumination (3.1.3.) the increase after the second illumination seems not absolutely dependent on protein synthesis by cytoplasmic 


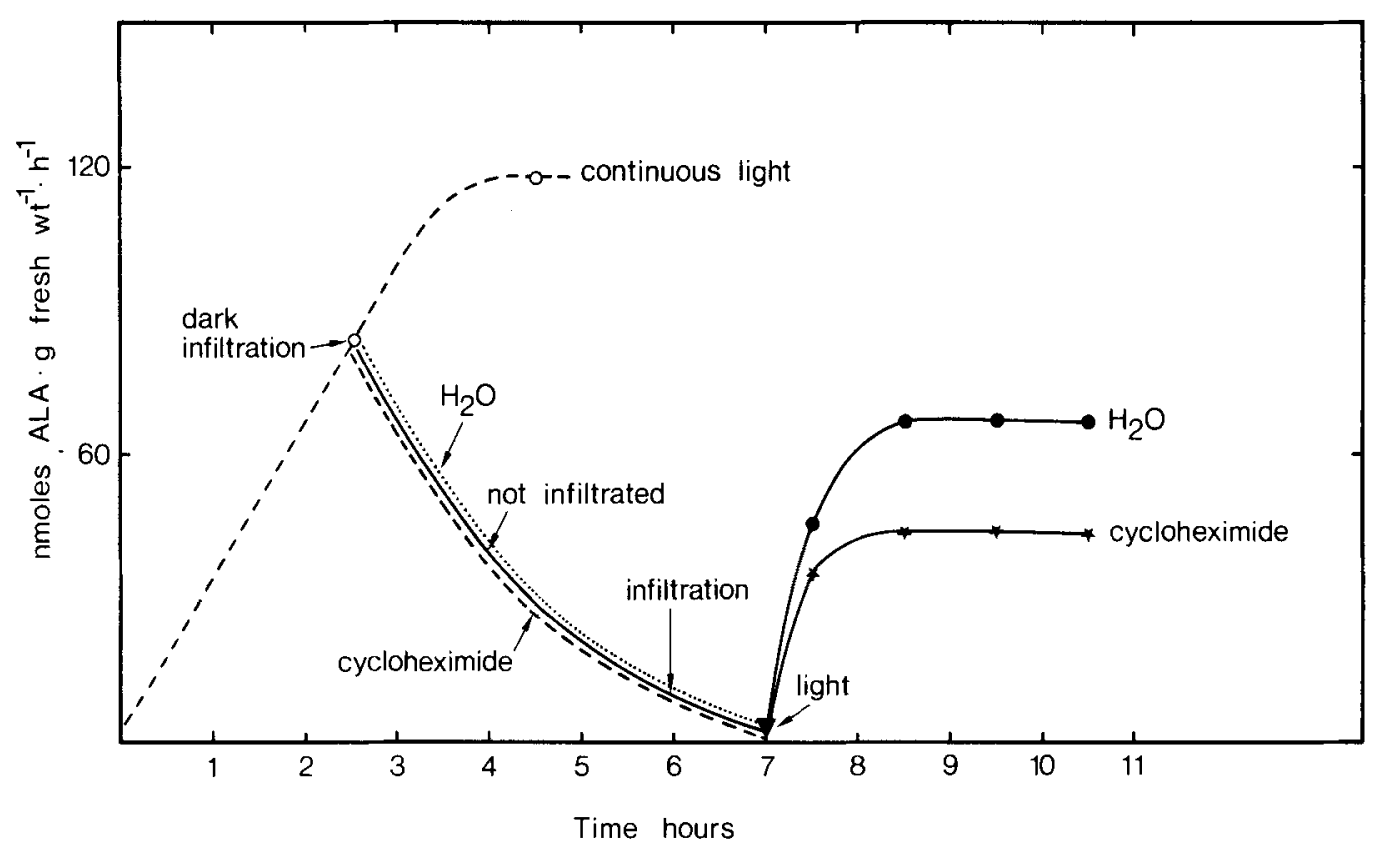

Figure 7. The effect of cycloheximide on the rate of ALA accumulation in the presence of levulinate. Duplicate samples of dark grown shoots were treated with levulinate as before and exposed to high light intensity at time 0 . After 2.5 hours some of the shoots remained in the light whereas most of them were returned to the dark. These were divided into three groups. The first group was vacuum infiltrated (2.3.) with distilled water (dottet line) and the second group with $100 \mu \mathrm{g} \cdot \mathrm{ml}^{-1}$ cycloheximide (broken line). ALA accumulation was determined at hour 7 . The third group (solid line) was not infiltrated. Of these some were infiltrated at hour 6 with distilled water or 100 $\mu \mathrm{g} \cdot \mathrm{ml}^{-1}$ cycloheximide and then re-illuminated from hour 7 .

ribosomes. A large portion of the decay in the ALA forming capacity is accordingly due to reversible inhibition of the enzymes concerned. The $35 \%$ reduction in the maximal rate obtained in the presence of cycloheximide indicates however a considerable breakdown of the ALA forming enzyme system during the 4.5 hours.

\subsection{The effect of DCMU on the formation of ALA in continuous light}

The rate of ALA formation was determined by infiltrating shoots with levulinate at various times after the onset of greening and measuring the amount of ALA formed during a period of 2 hours (Figure 8). Increasing rates were measured up to 6 hours of greening, when 70 nmole ALA were formed per hour. After 10 hours the rates decreased. ALA formation in continuous light is initially only slightly sensitive to $10^{-4}$-M-DCMU (Figure 8 ), but progressive inhibition is observed with time during greening and reaches $45 \%$ at 18 hours. ALA formation is thus initially independent of photosynthesis but becomes more dependent during greening.

In Figure 8 approximations for the rates of chlorophyll formation in this experiment are presented in ALA equivalents. The rates were obtained by measuring the chlorophyll content at the end of the levulinate treatment. As levulinate inhibits chlorophyll synthesis partially in the two hours of incubation the rates are characteristic for the beginning of the period of levulinate treatment. The rates of ALA and chlorophyll formation change in a coordinated way during this greening experiment. 


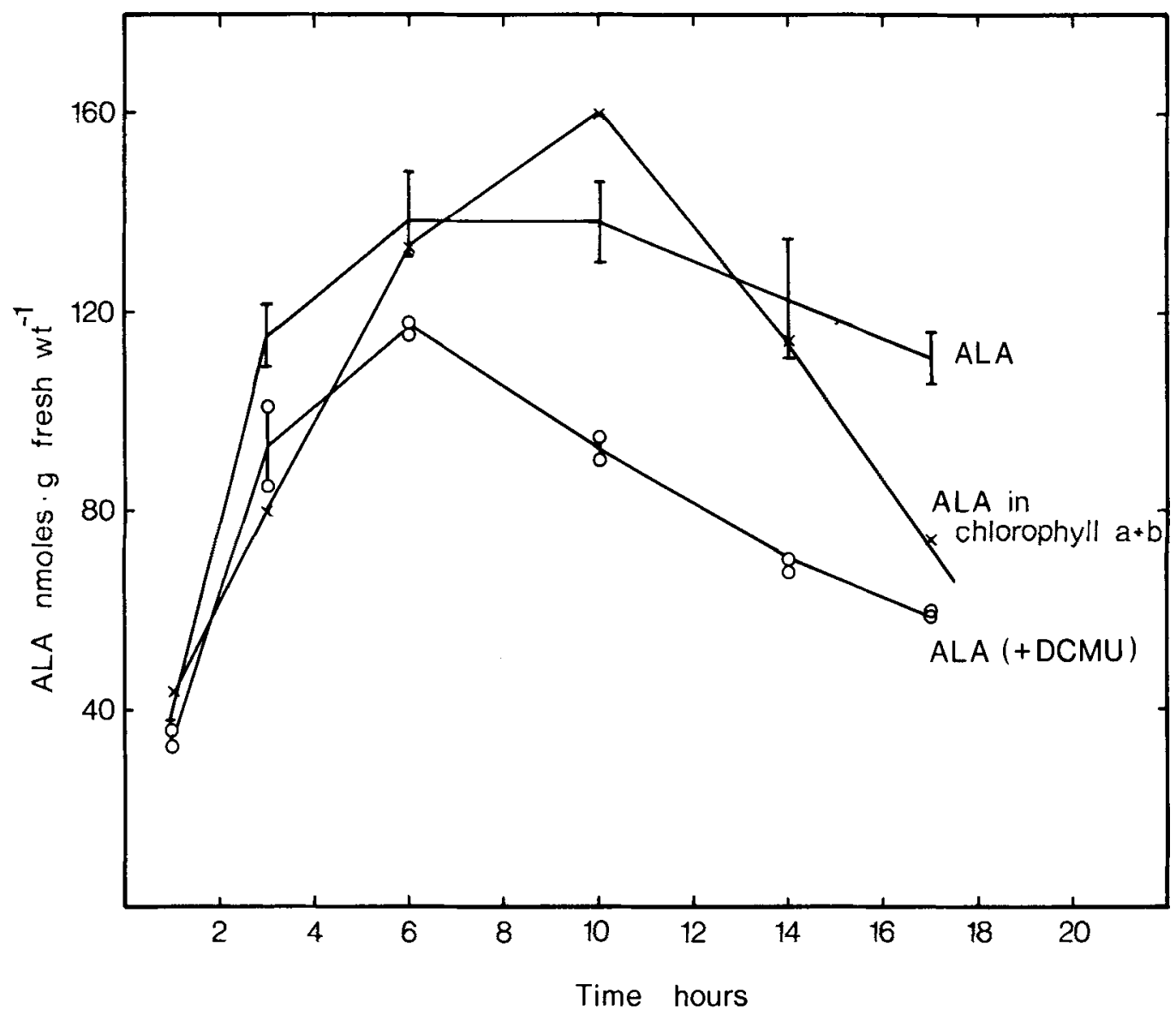

Figure 8. Rates of ALA formation during greening and the effect of DCMU. Dark grown shoots were immersed with their cut ends in distilled water and allowed to green in high light intensity. At various times the shoots were vacuum infiltrated (2.3.) in $20 \mathrm{mM}-\mathrm{Na}$ levulinate at $\mathrm{pH} 6.5$ with or without $10^{-4} \mathrm{M}-\mathrm{DCMU}$. After dipping their cut ends in the infiltrating solutions the shoots were allowed to accumulate ALA for 2 hours. The rates of chlorophyll formation shown are determined from the levels of chlorophyll observed in the infiltrated leaves at the end of the 2 hour incubation on levulinate. All values are plotted in the middle of the two hour incubation period. Rates are per hour and per 2 hours for chlorophyll and ALA, respectively.

\section{DISCUSSION}

Light has three effects on ALA formation in dark-grown barley seedlings. It causes the synthesis of ALA by the enzymes present in the dark grown plant, it causes cytoplasmic protein synthesis leading to an increase in the rate of ALA production and in later stages of greening it stimulates ALA formation through photosynthesis.
In the etioplasts of dark grown plants enzymes are present which form ALA from glutamate and glutamate-1-semialdehyde and their specific activity increases during greening (8). It is likely that these enzymes are responsible for the synthesis of ALA studied in the present experiments.

An increase in the amount of the ALA forming enzymes in the dark after a brief illumina- 
tion is apparent in barley leaves by the excessive formation of ALA when the conversion of ALA to porphobilinogen is inhibited with levulinate, since this increase can be prevented by cycloheximide (3.1.3.). Excessive formation of ALA in the presence of levulinate is also characteristic for dark grown maize leaves after a brief illumination (10). In the absence of levulinate this increase of the amount of ALA forming capacity cannot be seen directly in vivo, but becomes apparent upon a second continuous illumination after the appropriate dark period. The synthesis of chlorophyll then proceeds at a higher rate than in seedlings not preilluminated. This phenomenon is generally called elimination of the lag phase of chlorophyll synthesis (e.g. 13). Lack of excessive ALA or protochlorophyllide formation in the dark after a brief illumination in the absence of levulinate thus is due to inhibition, probably feedback inhibition of the ALA forming enzymes. Such feedback inhibition has been demonstrated by returning greening leaves of maize into darkness (3) and it has been suggested that protochlorophyllide is the responsible effector (3). The results reported in this paper are not contradictory to the view that protochlorophyllide or protochlorophyllide holochrome effect the feedback inhibition. In the maize experiments protochlorophyllide regeneration was slower in the presence of levulinate than in its absence and the slower rate of protochlorophyllide formation was correlated with excessive accumulation of ALA. In the barley experiment feedback inhibition of ALA synthesis in the dark with levulinate present did not take effect until full levels of convertible protochlorophyllide were regenerated. The increasing rate of ALA production caused by light can be inhibited by $100 \mu \mathrm{g} \cdot \mathrm{ml}^{-1}$ cycloheximide and thus reflects a synthesis of the ALAforming enzyme in the cytoplasm. High levels of cycloheximide affect both RNA and protein synthesis (2). Fifty $\mu \mathrm{g} \cdot \mathrm{ml}^{-1}$ cycloheximide inhibited the formation of ribosomal RNA but not of polyadenylatedRNA during greening of radish seedlings whereas $5 \mu \mathrm{g}$ cycloheximide were sufficient to block translation. In barley a concentration of $10 \mu \mathrm{g} \cdot \mathrm{ml}^{-1}$ cycloheximide sufficed to almost completely prevent the accu- mulation af ALA during the first 4 hours of greening. This concentration also strongly inhibited the incorporation of ${ }^{14} \mathrm{C}$-leucine into protein by the leaves (Gough \& BEALE, unpublished). Chloramphenicol an inhibitor of plastid protein synthesis did not influence ALA generation in the experiments with ALA formation in the dark which indicates etioplast protein synthesis to be dispensible. Since photosynthesis plays an increasing role in ALA biosynthesis at later stages of greening a long term effect of chloramphenicol is expected. In fact, chloramphenicol does inhibit chlorophyll synthesis during greening of barley when studied over 36 hours (13) and during greening of maize and bean leaves (11).

Actinomycin-D did not inhibit ALA formation in the dark after a brief illumination. Therefore if actinomycin-D penetrates the cells of dark-grown barley seedlings and activily inhibits transcription it can be concluded that the messenger RNA for ALA-forming enzymes is present in the dark-grown plant and that its translation is increased by light. The ability of actinomycin-D to inhibit RNA formation in vivo in greening beans is however, not very significant even at a 5-fold higher concentration than that used here (14). Conclusions about the absence of requirements of DNA-transcription for the formation of the ALA synthesizing enzymes must therefore await studies of messenger RNA formation in illuminated dark grown seedlings.

When the shoots are returned to the dark after the enzymes have been formed and a maximal rate of ALA generation obtained, the capacity of ALA formation decreases progressively in both maize seedlings (3) and barley seedlings (present paper). Upon re-illumination the capacity of ALA formation increases in both species. The rate and the amount of this increase can be varied experimentally with cycloheximide or differing dark periods. The interpretation of these data requires the assumption of both feedback inhibition and enzyme turnover.

The third effect of light on ALA biosynthesis may be connected with the provision of cofactors. Concentration of DCMU sufficient to inhibit cyclic and non-cyclic electron transport 
had a small effect on ALA generation at the early stages of greening but the inhibitory effect increased at later stages of greening. ALA formation from glutamate by plastids isolated from greening seedlings is inhibited by $3 \mu \mathrm{M}-\mathrm{DCMU}$ and has been shown to require NADPH and ATP (9).

These cofactors must be provided from some other source than photosynthesis in the dark or at the start of greening, perhaps by glycolysis with starch as the initial substrate. In particular NADPH and ATP may be provided by glyceraldehyde-3-P dehydrogenase and phosphoglyceric kinase. NADP-dependent glyceraldehyde 3-phosphate dehydrogenase undergoes reversible light activation and dark inactivation $(12,16)$ which could be related to the delayed increase in ALA forming capacity observed at the begining of the second illumination.

\section{ACKNOWLEDGEMENTS}

I am most grateful to Mss. NINA RASMUSSEN and ANN-SOFI STEINHOLZ for their technical assistance in the preparation of this paper, to Ms. E. Størling and Ms. Lena KongsRud for typing, to Dr. GAMINI KANNANGARA for discussions and in particular to Professor DITER VON WETTSTEIN for a critical reading of the manuscript.

\section{REFERENCES}

1. BEALE, $S$.: The biosynthesis of $\delta$-aminolevulinic acid in Chlorella. Plant Physiol. 45, 504-510 (1970)

2. Delseny, M., L. Aspart \& Y. Guitron: Effect of the protein synthesis inhibitor cycloheximide on RNA synthesis in radish seedlings. Biochimie 59 , $51-57$ (1977)

3. Fluhr, R., H. Harel, S. Klein \& E. Meller: Control of aminolevulinic acid and chlorophyll accumulation in greening maize leaves upon light-dark transitions. Plant Physiol. 56, 497-501 (1975)

4. GOUGH, S. P.: Defective synthesis of porphyrins in barley plastids caused by mutation in nuclear genes. Biochim. Biophys. Acta 286, 36-54 (1972)
5. Granick, S., S. Sassa, R. D. Lecere \& A. KAPPAS: Assays for porphyrins $\delta$-aminolevulinic acid dehydratase and porphyrinogen synthestase in microliter samples of whole blood: Applications to metabolic defects involving the heme pathway. Proc. Nat. Acad. Sci. U.S. 69, 2381-2385 (1972)

6. Harel, E. \& S. Klein: Light dependent formation of $\delta$-aminolevulinic acid in etiolated leaves of higher plants. Biochem. Biophys. Res. Commun. 49, 364-370 (1972)

7. Huffaker, R., R. L. Obendorf, C. J. Keller \& G. E. KLEINDORF: Effect of light intensity on photosynthetic carboxylative phase enzymes and chlorophyll synthesis in greening leaves of Hordeum vulgare L. Plant Physiol. 41, 913-918 (1966)

8. Kannangara, C. G \& S. P. Gough: Synthesis of $\delta$-aminolevulinic acid and chlorophyll by isolated chloroplasts. Carlsberg Res. Commun. 42, $441-457$ (1977)

9. Kannangara, C. G. \& S. P. Gough: Biosynthesis of $\delta$-aminolevulinate in greening barley leaves: Glutamate 1-semialdehyde aminotransferase. Carlsberg Res. Commun. 43, 185-194 (1978)

10. Klein, S., E. KatZ \& E. NeEman: Induction of $\delta$-aminolevulinic acid formation in etiolated maize leaves controlled by two light systems. Plant Physiol. 60, 335-338 (1977)

11. Klein, S., E. Harel, E. Neeman, E. Katz \& E. MELLER: Accumulation of $\delta$-aminolevulinic acid and its relation to chlorophyll synthesis and development of plastid structure in greening leaves. Plant Physiol. 56, 486-496 (1975)

12. MÚller, B., I. Zegler \& H. Zegler: Lichtinduzierte, reversible Aktivitätsteigerung der NADP-abhängigen Glycerinaldehyde-3-Phosphat Dehydrogenase im Chloroplasten. Eur. J. Biochem. 9, 101-106 (1967)

13. NADLER, K. \& S. GRANICK: Controls on chlorophyll synthesis in barley. Plant Physiol. 40, 240-246 (1970)

14. SMrTh, H.: Phytochrome-mediated assembly of polyribosomes in etiolated bean leaves. Eur. J. Biochem. 65, 161-170 (1970)

15. Vernon, L. P.: Spectroscopic determination of chlorophylls and pheophytins in plants extracts. Anal. Chem. 32, 1144-1150 (1960)

16. Ziegler, H \& I. Ziegler: Der Einfluss der Belichtung auf die NADP+-abhängige Glycerinaldehyde-3-Phosphate Dehydrogenase. Planta, $65,369-380(1975)$ 